\title{
Perfuração Intestinal por Enema Aquoso - Uma Complicação Pouco Conhecida
}

\section{Intestinal Perforation With Cleansing Enema - A Rare Condition}

\author{
VILMAR MOURALEAL ${ }^{1}$; CLÉCITON BRAGATAVARES²; KELSON JAMES SILVADEALMEIDA²; LARYSSAPORTELA \\ RAMOS MAGALHÃES REGO²; MORGANA EULÁLIOBARRETO SOARES ${ }^{2}$ \\ ${ }^{1}$ Cirurgião Geral do Hospital Getúlio Vargas, Professor adjunto da disciplina de Doenças \\ Infecto-Contagiosas e Parasitárias da Universidade Federal do Piauí; ${ }^{2}$ Estudante de Graduação em Medicina da \\ Universidade Federal do Piauí - Piauí - Brasil.
}

\begin{abstract}
LEAL VM; TAVARES CB; ALMEIDA KJS; REGO LPRM; SOARES MEB. Perfuração Intestinal por Enema Aquoso - Uma complicação Pouco Conhecida. Rev bras Coloproct, 2006;26(3): 325-327.

RESUMO: A perfuração intestinal é uma ocorrência freqüente nos serviços de emergência, sendo iatrogênica em $6 \%$ dos casos. Pode tratar-se de uma complicação do uso de enemas aquosos retrógrados; a qual é rara, não tendo, pois, incidência conhecida. Apresentamos o relato de um paciente de 69 anos que após submeter-se a enema aquoso para preparo intestinal, evoluiu com quadro de dor abdominal súbita, vômitos, sinais de irritação peritoneal e comprometimento do estado geral. Após laparotomia exploradora, constatou-se perfuração no reto. A importância do relato é atentar para uma grave e pouco conhecida complicação de um procedimento rotineiro, que muitas vezes não é diagnosticada pela falta de uma história clínica relevante ou omissão pelas instituições que temem implicações judiciais.
\end{abstract}

Descritores: Enema Aquoso, Perfuração Intestinal, Peritonite, Enema Retrógrado, Complicação.

\section{INTRODUÇÃO}

Perfuração iatrogênica do reto e do cólon sigmóide é um evento raro. Pode ser causada por colonoscopia, enema bárico, enema aquoso retrógrado (EAR) e inserção de corpo estranho. ${ }^{(1,2)}$

EAR são usados no tratamento de constipação crônica em pacientes idosos e acamados. Como resultado do uso freqüente, casos de perfuração do reto e sigmóide aumentaram, mas sua real incidência é desconhecida. ${ }^{(3)}$

A importância deste relato é atentar para uma grave e pouco conhecida complicação de um procedimento rotineiro, que muitas vezes não é diagnosticada pela falta de história clínica relevante.

\section{CASO CLÍNICO}

Paciente de 69 anos, masculino, com dor abdominal, náuseas, vômitos, redução da eliminação de flatos e constipação há uma semana. Ao exame: desidratado (++/4+), anictérico, afebril, abdome flácido, distendido, hipertimpânico e com ruídos hidro-aéreos aumentados.

Ao Rx de abdome evidenciou-se obstrução intestinal por volvo de sigmóide. Foi submetido à laparotomia quando se desfez o volvo e realizou-se tranversostomia.

$\mathrm{Na}$ véspera da cirurgia de abaixamento do cólon, o paciente foi submetido a preparo intestinal com EAR evoluindo com dor abdominal súbita, vômitos e sinais de irritação peritoneal. 
Na cirurgia de urgência, constatou-se perfuração posterior do terço médio do reto e enfisema parietal do reto(FIGURA 1), sigmóide e mesossigmóide. Fezse hemicolectomia esquerda ampliada com manutenção da transversostomia, e fechamento do coto retal. (FIGURA 2).

O paciente teve boa evolução e foi reoperado 10 meses após, quando se realizou abaixamento do cólon à Duhamel-Haddad. O paciente encontra-se com boa função intestinal, porém desenvolveu tardiamente hérnia incisional.

\section{DISCUSSÃO}

Várias doenças resultam em perfuração de cólon, sendo a principal a diverticulite. ${ }^{(4)}$ Uma causa rara é a perfuração por EAR, cuja incidência exata é impossível de estabelecer. Os locais de perfuração são cólon sigmóide e o reto. ${ }^{(1,3)}$

Os sintomas de perfuração cólon-retal são variáveis, sendo dor abdominal o mais comum. Sangramento retal, febre e macicez abdominal ao nível da região do sigmóide e ou reto podem aparecer. ${ }^{(1)}$ Às vezes, o quadro pode iniciar com sinais de peritonite, sepse e choque, ou ser assintomático (10\% dos ca$\operatorname{sos})^{(1,3)}$

O diagnóstico é principalmente clínico. Contudo, a história do uso de enema pode não ser fornecida porque os pacientes são freqüentemente muito idosos ou dementes e às vezes as instituições em que o pro-

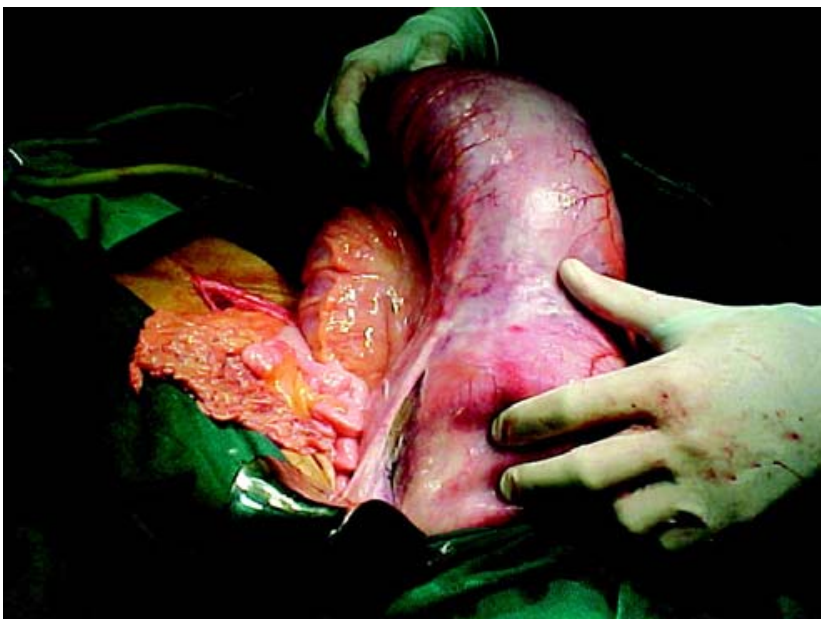

Figura 1 - Área de perfuração intestinal na porção posterior do terço médio do reto. cedimento foi realizado omitem esta informação, temendo implicações judiciais. ${ }^{(1,3)}$

Entre os exames de imagem, o diagnóstico pode ser feito por Raios-X simples ou Tomografia Computadorizada de abdômen, a mais sensível. ${ }^{(1,3)} \mathrm{A}$ gravidade do quadro clínico, o conhecimento da administração do enema e desta possível complicação justificaram a laparotomia exploradora neste caso.

Quando a perfuração é proximal à reflexão peritoneal, o segmento lacerado deve ser ressecado e o procedimento de Hartmann realizado. Sendo no reto extraperitoneal, além da colostomia, associa-se drenagem pré-sacral. ${ }^{(3)}$

Adota-se tratamento conservador quando há pequena perfuração retal retroperitoneal, ausência de fezes no trato gastrointestinal e no retroperitôneo e o paciente apresenta-se com boas condições clínicas. Consiste de terapia de suporte, nutrição parenteral total, drenagem do assoalho pélvico, se necessário, antibioticoterapia de largo espectro e seguimento do paciente. ${ }^{(5)}$

O paciente encontra-se bem, o que só foi possível devido ao diagnóstico precoce e tratamento agressivo realizados. Justifica-se esta conduta por saber-se que perfurações traumáticas de cólon e reto podem implicar em relativo bom prognóstico independentemente da idade, das condições clínicas prévias e dos achados durante a cirurgia. ${ }^{(3)}$

Enfatiza-se a importância do conhecimento dos riscos deste procedimento, que é de certa forma invasivo e utilizado corriqueiramente.

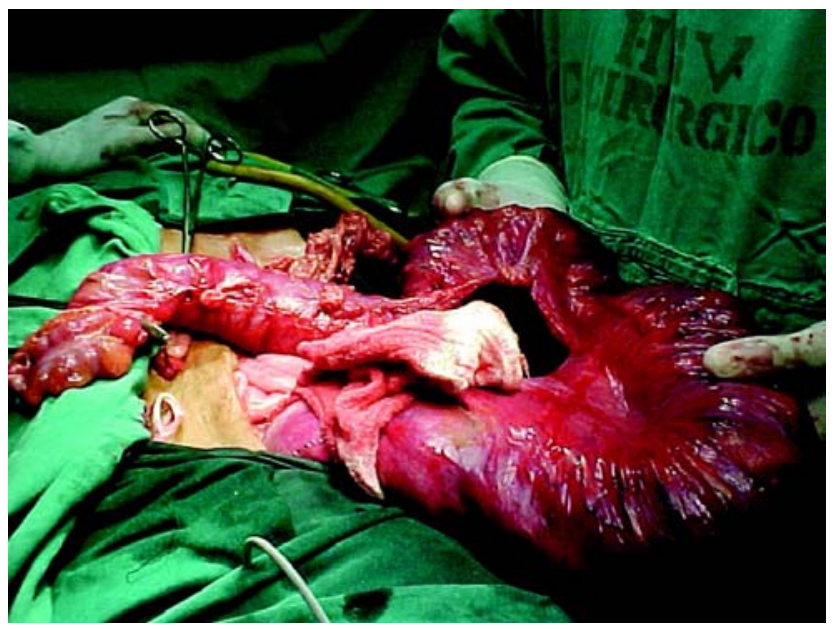

Figura 2 - Porção do cólon esquerdo que será retirada e transversostomia mantida. 
ABSTRACT: Intestinal perforation is a rare complication of retrograde cleansing enemas and its incidence is unknown. We relate the case of a 69 years old patient that underwent a surgery for intestinal obstruction. Afterwards, during preparation for colostomy withdrawal with use of cleansing enema, he showed signals of peritonitis. Therefore, we should remember this possible and grave complication, sometimes not diagnosed for an absent clinical history, and at the same time to propose an aggressive conduct in order to improve the prognosis.

Key words: Cleansing Enema, Retrograde Enema, Intestinal Perforation, Peritonitis, Complication.

\section{REFERÊNCIAS}

1. Gayer G, Zissin R, Oscadchy A, Hertz M. Perforations of the rectosigmoid colon Induced by cleasing enema: CT findings in 14 patients. Abdom Imaging 2002; 27:453-7.

2. Topcu T. Colorectal perforation due to self administered retrograde enema. Ulus Travma Derg. 2003; 9(4):297-9.

3. Paran H, Butnaru G, Neufeld D, Magen A, Freund U. Enemainduced perforation of the rectum in chronically constipated patients. Dis Colon Rectum 1999; 42 (12): 1609-12.

4. Biondo S, Pares D, Marti Rague J, De Oca J, Toral D, Borobia FG, et al. Emergency operations for nondiverticular perforation of the left colon. Am J Surg 2002; 183(3):256-60.
5. Madhala O, Greif F, Cohen M, Lelcuk S. Major Rectal Perforations Caused by Enema: Is Surgery Mandatory? Digestive Surgery 1998; 15:270-2.

\section{Endereço para correspondência:} VILMAR MOURA LEAL

Rua Tabelião José Basílio, 1248 - Bairro Jockey 64.048-190 - Teresina (PI) - Brasil

E-mail: vilmar@yahoo.com.br vilmarmoura@hotmail.com vilmarml@ufpi.br 